\title{
Combination of ions promotes cell migration via extracellular signal-regulated kinase $1 / 2$ signaling pathway in human gingival fibroblasts
}

\author{
KIMIKO YAMAGUCHI-UEDA ${ }^{1}$, YUKI AKAZAWA ${ }^{1}$, KEITA KAWARABAYASHI ${ }^{1}$, ASUNA SUGIMOTO ${ }^{1}$, \\ HIROSHI NAKAGAWA ${ }^{1}$, AYA MIYAZAKI ${ }^{1}$, RIKA KUROGOUSHI ${ }^{1}$, KOKORO IWATA ${ }^{1}$, TAKAMASA KITAMURA ${ }^{1}$, \\ AYA YAMADA $^{2}$, TOMOKAZU HASEGAWA ${ }^{1}$, SATOSHI FUKUMOTO $^{2}$ and TSUTOMU IWAMOTO ${ }^{1}$ \\ ${ }^{1}$ Department of Pediatric Dentistry, Institute of Biomedical Sciences, Tokushima University Graduate School, \\ Tokushima 770-8504; ${ }^{2}$ Division of Pediatric Dentistry, Department of Oral Health and Development Sciences, \\ Tohoku University Graduate School of Dentistry, Sendai 980-8575, Japan
}

Received September 26, 2018; Accepted April 3, 2019

DOI: $10.3892 / \mathrm{mmr} .2019 .10141$

\begin{abstract}
Wound healing is a dynamic process that involves highly coordinated cellular events, including proliferation and migration. Oral gingival fibroblasts serve a central role in maintaining oral mucosa homeostasis, and their functions include the coordination of physiological tissue repair. Recently, surface pre-reacted glass-ionomer (S-PRG) fillers have been widely applied in the field of dental materials for the prevention of dental caries, due to an excellent ability to release fluoride (F). In addition to F, S-PRG fillers are known to release several types of ions, including aluminum (Al), boron (B), sodium $(\mathrm{Na})$, silicon $(\mathrm{Si})$ and strontium $(\mathrm{Sr})$. However, the influence of these ions on gingival fibroblasts remains unknown. The aim of the present study was to examine the effect of various concentrations of an S-PRG filler eluate on the growth and migration of gingival fibroblasts. The human gingival fibroblast cell line HGF-1 was treated with various dilutions of an eluent solution of S-PRG, which contained $32.0 \mathrm{ppm} \mathrm{Al}$, 1,488.6 ppm B, 505.0 ppm Na, 12.9 ppm Si, 156.5 ppm Sr and 136.5 ppm F. Treatment with eluate at a dilution of 1:10,000 was observed to significantly promote the migration of HGF-1 cells. In addition, the current study evaluated the mechanism underlying the mediated cell migration by the S-PRG solution and revealed that it activated the phosphorylation of extracellular signal-regulated kinase 1/2 (ERK1/2), but not of p38. Furthermore, treatment with a MEK inhibitor blocked the
\end{abstract}

Correspondence to: Dr Tsutomu Iwamoto, Department of Pediatric Dentistry, Institute of Biomedical Sciences, Tokushima University Graduate School, 3-18-15 Kuramoto-cho, Tokushima 770-8504, Japan

E-mail: iwamoto@tokushima-u.ac.jp

Key words: gingival fibroblasts, cell migration, extracellular signal-regulated kinase signaling, multiple-ion solution, surface pre-reacted glass-ionomer filler cell migration induced by the solution. Taken together, these results suggest that S-PRG fillers can stimulate HGF-1 cell migration via the ERK1/2 signaling pathway, indicating that a dental material containing this type of filler is useful for oral mucosa homeostasis and wound healing.

\section{Introduction}

Human gingival fibroblasts (HGFs) are the most abundant resident cells in the periodontal tissue (1), and serve pivotal roles in the maintenance of tissues and oral wound healing. When tissue damage occurs, the wound healing process begins immediately to prevent further damage or infection. This is a well-coordinated complex process that involves four sequential overlapping phases, including hemostasis, inflammation, proliferation and remodeling (2), which are orchestrated by cross-talking of various cytokines, chemokines, growth factors and cells that participate in the process (3). Among these, the proliferation phase is characterized by migration and subsequent proliferation of fibroblasts, and is important for proper healing and rebuilding of damaged areas in the wound. Subsequently, fibroblasts secrete a new collagen matrix and participate in wound closure by formation of granulation tissue in preparation for the last remodeling phase. Thus, fibroblasts have crucial roles in wound healing, and elucidation of their associated characteristics is anticipated to lead to the development of appropriate therapeutic agents.

Surface pre-reacted glass-ionomer (S-PRG) fillers contain a stable glass ionomer that is generated by the reaction of fluoroaluminosilicate glass with polyacrylic acid (4). These fillers have been developed as GIOMER products for use as dental materials, such as fissure sealants (5), direct filing composite resins (6), and tooth bonding and coating materials (7). S-PRG fillers are characterized by the ability to release and recharge fluoride $(\mathrm{F})$, which makes them attractive materials for the prevention of secondary dental caries (4). Furthermore, S-PRG fillers release multiple other ions, including aluminum $(\mathrm{Al})$, boron $(\mathrm{B})$, sodium $(\mathrm{Na})$, silicon $(\mathrm{Si})$, and strontium $(\mathrm{Sr})$, which have been reported to be effective in the prevention of oral bacteria adhesion (8), 
suppression of biofilm formation (9), resistance to acid demineralization (10) and protection against dental caries $(5,11,12)$. Recently, an eluate solution from S-PRG fillers was demonstrated to have a suppressive effect on periodontal disease in model mice (13). Thus, the use of S-PRG fillers containing dental materials may benefit oral health. However, to the best of our knowledge, no known studies have examined the influence of the multiple ions released from such fillers on HGFs.

In the current study, the effects of multiple ions released from S-PRG fillers on the proliferation, migration and signaling of the HGF-1 cell line were investigated. This is the first report to demonstrate the promotion of HGF-1 migration via the extracellular signal-regulated kinase 1/2 (ERK1/2) signaling pathway, induced by multiple ions present in the solution eluted from S-PRG fillers. These results suggested that the combination of multiple ions promotes cell migration, which assists in oral wound healing.

\section{Materials and methods}

Reagents. The mitogen-activated protein kinase kinase (MEK) inhibitor U0126 (cat. no. 9903), anti-p44/42 antibody (cat. no. 9102), anti-phosphorylated (p)-p44/42 antibody (cat. no. 9101S), anti-p38 MAPK antibody (cat. no. 86905), anti-p-p38 MAPK antibody (cat. no. 9215) and horseradish peroxidase (HRP)-conjugated anti-rabbit immunoglobulin G secondary antibody (cat. no. 7074) were purchased from Cell Signaling Technology, Inc. (Danvers, MA, USA). The p38 mitogen-activated protein kinase (MAPK) inhibitor SB203580 (cat. no. 152121-47-6) and $\beta$-actin antibody (cat. no. GTX629630) were purchased from Wako Pure Chemical Industries, Ltd. (Osaka, Japan) and GeneTex, Inc. (Irvine, CA, USA), respectively. The multiple-ion solution (cat. no. 041402) eluted from S-PRG fillers was provided by Shofu Dental Corporation (Kyoto, Japan). For the preparation of the multiple-ion solution, S-PRG filler was mixed with an equal volume of distilled water by a tumbler mixer at $23^{\circ} \mathrm{C}$ for $24 \mathrm{~h}$, followed by centrifugation at $3,000 \mathrm{x} \mathrm{g}$ and $23^{\circ} \mathrm{C}$ for $6 \mathrm{~h}$ to separate the filler and the liquid. Next, the supernatant was filtered to remove any residual insoluble material and used as the S-PRG elute. The multiple-ion solution contained 32.0 ppm Al, 1,488.6 ppm B, 505.0 ppm Na, 12.9 ppm Si, $156.5 \mathrm{ppm} \mathrm{Sr}$ and $136.5 \mathrm{ppm}$ F. The S-PRG elute was diluted with a 1:1 mixture of Dulbecco's Modified Eagle's medium (DMEM) and F12 nutrient mixture (DMEM/F-12, Gibco; Thermo Fisher Scientific, Inc., Waltham, MA, USA) at various dilution ratios $(0,1: 100,1: 1,000$ and 1:10,000).

Cell culture. HGF-1 cells were purchased from ScienCell Research Laboratories, Inc. (cat. no. 2620; San Diego, CA, USA). The cells were cultured in DMEM/F-12, supplemented with $10 \%$ fetal bovine serum (FBS; Biowest, Nuaille, France). Cultured fibroblasts were maintained at $37^{\circ} \mathrm{C}$ in a humidified atmosphere of $5 \% \mathrm{CO}_{2}$. For the experiments, $\mathrm{HGF}-1$ cells were cultured in DMEM/F-12 containing the multiple ion solution at various dilution ratios.

Cell proliferation. The influence of the multiple-ion solution on HGF-1 cell proliferation was assessed using a Cell Counting Kit-8 (CCK-8) purchased from Dojindo Molecular
Technologies, Inc. (Kumamoto, Japan). Briefly, cells were seeded into a 96-well plate at a density of 1,000 cells/well, and then incubated with various dilutions of the multiple-ion solution $(0,1: 100,1: 1,000$ and 1:10,000) for 24,48 or $72 \mathrm{~h}$. At each time point, $10 \mu \mathrm{l}$ of solution from the CCK-8 kit was added to each well and then incubation was continued in an atmosphere that included $5 \% \mathrm{CO}_{2}$ at $37^{\circ} \mathrm{C}$ for $1 \mathrm{~h}$. The absorbance at $450 \mathrm{~nm}$ was measured using a plate reader (MultiSkan FC Basic; Thermo Fisher Scientific, Inc.).

Cell proliferation was also assessed using a cell count method. For this, HGF-1 cells were seeded at a density of $1.0 \times 10^{3}$ cells/well in a 24 -well plate and maintained with various concentrations of the multiple-ion solution $(0,1: 100,1: 1,000$ and $1: 10,000)$ for 24,48 or $72 \mathrm{~h}$. Subsequently, the total cell number was counted in ten randomly selected fields of view in a 24-well plate under an inverted microscope (magnification, x20).

Cell migration. For in vitro cell migration assays, ibidi Culture-Inserts (ibidi GmbH, Martinsried, Germany) were used in a $35 \mathrm{~mm}$ dish. The ibidi Culture-Insert has two cell culture wells, which are separated by a $500-\mu \mathrm{m}$ wall. HGF-1 cell suspension $\left(70 \mu \mathrm{l} ; 5 \times 10^{5}\right.$ cells $\left./ \mathrm{ml}\right)$ was added to each well on the two sides of the culture insert and cultured with DMEM/F-12 supplemented with $10 \% \mathrm{FBS}$ for $24 \mathrm{~h}$ at $37^{\circ} \mathrm{C}$. Then, the Culture Insert was gently removed with sterile tweezers, and cells were cultured with various concentrations of the multiple-ion solution $(0,1: 100,1: 1,000$ and 1:10,000) in medium containing 5 or $10 \%$ FBS for 12,16 and $22 \mathrm{~h}$ at $37^{\circ} \mathrm{C}$. Cell migration was observed and recorded using a Nikon inverted microscope system (Nikon ECLIPSE TE2000-U; Nikon Corporation, Tokyo, Japan). To quantify cell migration, the uncovered area in which no cells were present was measured using ImageJ 1.48v (National Institutes of Health, Bethesda, MD, USA).

Furthermore, in order to assess the effect of inhibitors on cell migration, HGF-1 cells were cultured in the presence of the multiple-ion solution (diluted to $1: 10,000)$ with or without $10 \mu \mathrm{M}$ U0126 (MEK inhibitor) or SB203580 (p38 MAPK inhibitor). Subsequently, cell migration was examined as mentioned earlier. An equivalent volume of dimethyl sulfoxide was used as control treatment.

Western blotting. Following serum deprivation for $1 \mathrm{~h}, \mathrm{HGF}-1$ cells were cultured in the presence of the multiple-ion solution (diluted to 1:10,000) for various time periods and then washed three times with ice-cold phosphate-buffer saline containing $1 \mathrm{mM}$ sodium vanadate $\left(\mathrm{Na}_{3} \mathrm{VO}_{4}\right)$. Next, the cells were solubilized with lysis buffer (containing $10 \mathrm{mM}$ Tris- $\mathrm{HCl}, \mathrm{pH} 7.4$, $150 \mathrm{mM} \mathrm{NaCl}, 10 \mathrm{mM} \mathrm{MgCl} 2,0.5 \%$ Nonidet P-40, $1 \mathrm{mM}$ phenylmethylsulfonyl $\mathrm{F}$ and 20 units/ml aprotinin). The lysed cells were centrifuged at $11,177 \mathrm{x}$ g for $5 \mathrm{~min}$ at $4^{\circ} \mathrm{C}$, and the protein concentration in each sample was measured using a micro-BCA protein assay reagent (Pierce; Thermo Fisher Scientific, Inc.). The samples were then denatured in SDS sample buffer, and $20 \mu \mathrm{g} /$ lane of lysate protein was separated via $12 \%$ SDS-PAGE. Following separation, the proteins were transferred onto a PVDF membrane and blocked with 5\% blocking solution (Cell Biolabs, Inc., San Diego, CA, USA) in PBS-0.05\% Tween 20 for $1 \mathrm{~h}$ at room temperature (RT). Then, the blotted membrane was incubated for $1 \mathrm{~h}$ at RT using 

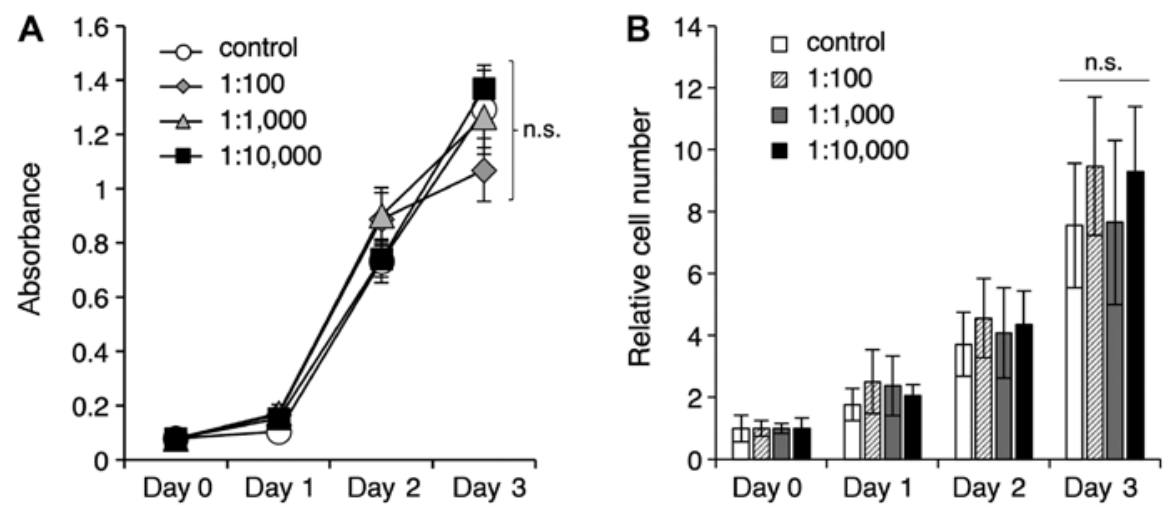

Figure 1. Eluted solution from S-PRG filler containing multiple ions has no effects on HGF-1 proliferation. HGF-1 cells were cultured with various dilutions of the multiple-ion solution $(0,1: 100,1: 1,000$ and 1:10,000) for 3 days. (A) Cell Counting Kit- 8 assay and (B) a cell count method were used to assess cell proliferation. Values are presented as the mean \pm standard error of the mean ( $n=8$ in assay $A$ and $n=10$ in assay B). Repeatability of the results obtained experimentally was confirmed by performing three independent trials. S-PRG, surface pre-reacted glass-ionomer; HGF, human gingival fibroblast; n.s., not significant.

primary antibodies (anti-p44/42, anti-p-p44/42, anti-p38 MAPK, anti-p-p38 MAPK and anti- $\beta$-actin; all 1:1,000 in the blocking solution). Membranes were subsequently incubated with the HRP-conjugated secondary antibody $(1: 2,000)$ for $1 \mathrm{~h}$ at RT. Subsequently, samples were visualized using an enhanced chemiluminescence kit (GE Healthcare Life Sciences, Little Chalfont, UK). The blot images were acquired using an Amersham Imager 600 (GE Healthcare Life Sciences).

Statistical analysis. All experiments were repeated at least three times. All values are presented as the mean \pm standard error of the mean. Comparisons between more than two groups were assessed with analysis of variance, followed by Bonferroni multiple comparisons test. Comparisons between two groups were conducted with Student's t-test. Differences with $\mathrm{P}<0.05$ were considered as statistically significant.

\section{Results}

$S-P R G$ filler solution has no effect on cell proliferation. The solution eluted from the S-PRG filler contained multiple ions, including F, Al, B, Na, Si, and Sr. Initially, the study examined whether this multiple-ion solution at various dilution ratios (1:100, 1:1,000 and 1:10,000) had an effect on the proliferation of HGF-1 cells after 24, 48, and $72 \mathrm{~h}$ using a CCK-8 assay (Fig. 1A) and a cell count method (Fig. 1B). At the final time point of $72 \mathrm{~h}$ that was examined in the current study, no significant differences were observed in regard to cell proliferation between the control and experimental groups (Fig. 1). These results suggested that the multiple-ion solution eluted from S-PRG fillers did not have an effect on the proliferation of gingival fibroblasts.

$S-P R G$ filler solution promotes cell migration. Proper wound healing requires fibroblast migration; thus, a cell migration assay was conducted in the present study using culture inserts to examine whether the multiple-ion solution eluted from the S-PRG filler had an effect on cell migration. HGF-1 cells were cultured with various dilutions of the multiple-ion solution $(1: 100,1: 1,000$ and $1: 10,000)$ in medium containing $5 \%$ or $10 \%$ FBS for 12,16 or $22 \mathrm{~h}$. The results revealed that medium containing multiple-ion solution at a dilution of 1:10,000 and $5 \%$ FBS exhibited significant promotion of cell migration at
$16 \mathrm{~h}$ of incubation, as compared with the control cells (Fig. 2); however, other conditions did not induce an increase in cell migration. These results suggested that the multiple-ion solution eluted from the S-PRG filler promoted the migration of gingival fibroblasts in a concentration and time-dependent manner.

ERK signaling pathway is involved in fibroblast migration induced by S-PRG filler solution. The effect of the multiple-ion solution eluted from the S-PRG filler on intracellular signaling was also examined. MAPKs, including ERK, p38 MAPK and Jun N-terminus kinase (JNK), have a principal role in cell migration (14). In addition, a previous study has suggested that sodium fluoride strongly induced the activation of ERK1/2 and ERK5 signal transduction, rather than that of JNC and p38 in MC3T3-E1 cells (15). Therefore, the current study examined whether the multiple ion-containing solution eluted from the S-PRG filler induced the phosphorylation of ERK1/2 proteins. Marked ERK 1/2 phosphorylation was observed at 5 min after stimulation with the diluted multiple-ion solution, whereas p38 MAPK phosphorylation was not induced at any of the investigated time points up to 60 min after treatment (Fig. 3). These results indicated that activation of ERK1/2, but not p38 MAPK, may be involved in the promotion of HGF-1 cell migration by the multiple-ion solution. Furthermore, the study examined whether the MEK inhibitor U0126 had an effect on cell migration induced by the S-PRG filler solution. Clear inhibition of cell migration was observed following the addition of U0126, as compared with the control (Fig. 4A and B). To confirm the inhibition of ERK activity by U0126, western blotting was performed in cells treated with U0126. It was observed that U0126 evidently inhibited the phosphorylation of ERK1/2 in HGF-1 cells (Fig. 4C). By contrast, the p38 MAPK inhibitor SB203580 had no effect on cell migration (Fig. 4D and E) and the phosphorylation of p38 MAPK (Fig. 4F) in HGF-1 cells. Since phosphorylation of p38 MAPK was not observed in HGF-1 cells treated with a multiple ion-containing solution (Fig. 3), p38 MAPK signaling may not be involved in HGF-1 cell migration. Thus, these results suggested that the multiple-ion solution may promote the migration of gingival fibroblasts via an intracellular ERK1/2 signaling pathway. 
A

$12 \mathrm{~h}$

$10 \%$ FBS
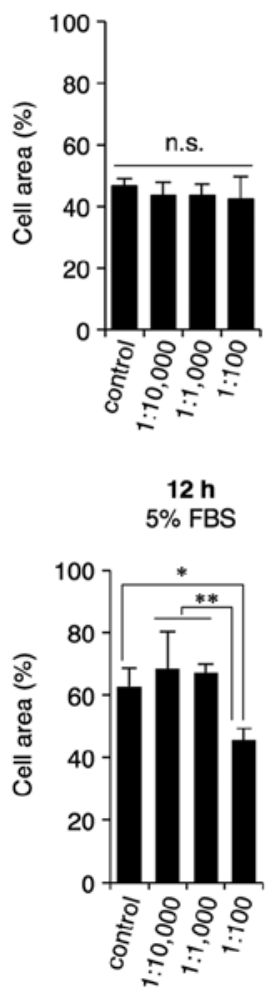

$16 \mathrm{~h}$

$10 \%$ FBS
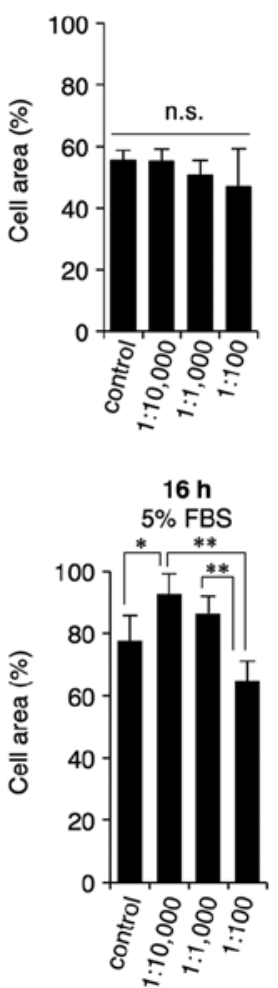
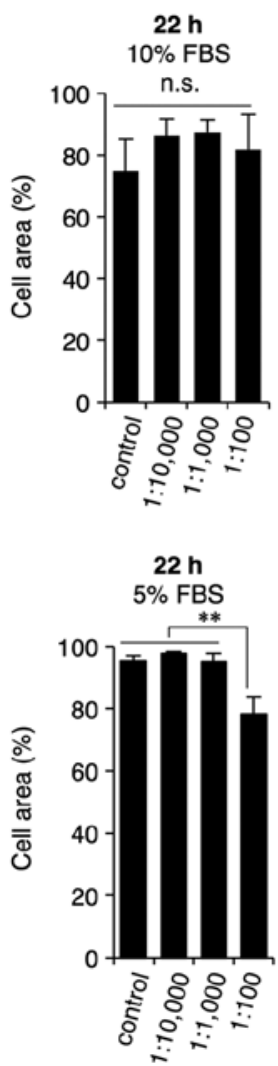

B

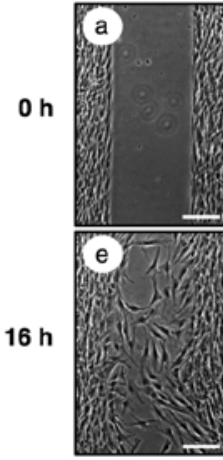

control

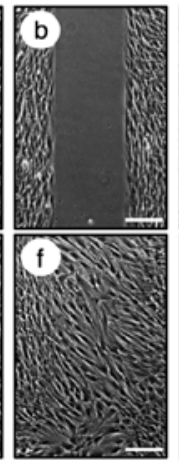

1:10,000

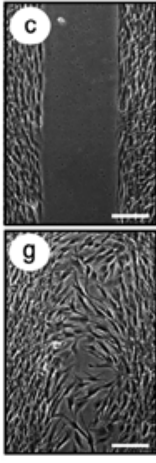

$1: 1,000$

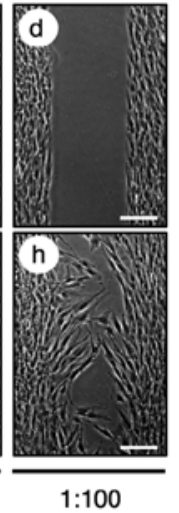

Figure 2. Eluted solution from S-PRG filler containing multiple ions promotes HGF-1 migration. HGF-1 cells were seeded into wells on both sides of a cell culture insert, cultured for $24 \mathrm{~h}$ and then exposed to the multiple-ion solution at various dilutions $(0,1: 100,1: 1,000$ and $1: 10,000)$ containing 5 or $10 \%$ FBS at 12,16 and $22 \mathrm{~h}$ for cell migration analysis. (A) Cell area graphs and (B) images of cell culture (magnification, $\mathrm{x} 20$; scale bar, $200 \mu \mathrm{m}$ ) at different conditions are shown. Medium containing the multiple-ion solution diluted at a ratio of 1:10,000 and supplemented with 5\% FBS was observed to significantly promote cell migration as compared with the control cells at $16 \mathrm{~h}$. To quantify cell migration, the uncovered area was measured using Image $\mathrm{J}$ software. Values are expressed as the mean \pm standard error of the mean $(n=4)$. Repeatability of the results obtained experimentally was confirmed by performing three independent trials ${ }^{*} \mathrm{P}<0.05$ and ${ }^{* *} \mathrm{P}<0.01$. S-PRG, surface pre-reacted glass-ionomer; HGF, human gingival fibroblast; n.s., not significant.

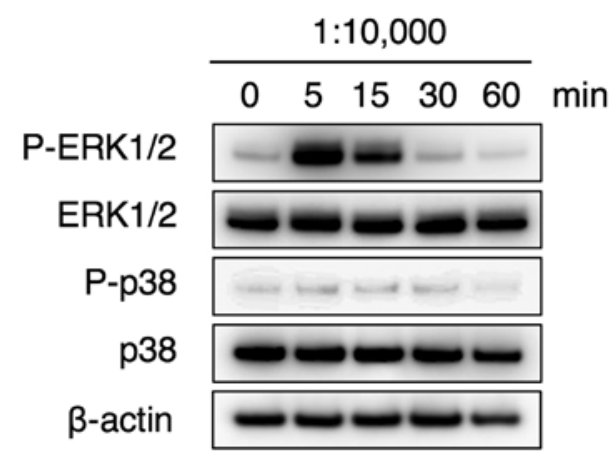

Figure 3. Phosphorylation or ERK and p38 following treatment with multiple ion solution. Following serum deprivation for $1 \mathrm{~h}$, phosphorylation of ERK1/2 in cells was induced by incubation with the solution containing multiple ions that was eluted from the S-PRG filler (dilution, 1:10,000). The time course of ERK1/2 and p38 phosphorylation was analyzed by western blotting. S-PRG, surface pre-reacted glass-ionomer; ERK1/2, extracellular signal-regulated kinase $1 / 2 ; \mathrm{p}-$, phosphorylated.

\section{Discussion}

The oral cavity functions as an entry way for the digestive and respiratory systems, in addition to its important roles in daily activities, such as eating, speaking and breathing; thus, it is often exposed to various stimuli or injuries from contact with external factors. Gingival fibroblasts serve crucial roles in maintaining tissue homeostasis and recovery to a normal condition following acute inflammation, migrating to the wound site and proliferating in order to reconstitute connective tissue, events that are regulated by various growth factors and cytokines, including epidermal growth factor (16), basic fibroblast growth factor (bFGF) (17), platelet-derived growth factor (PDGF) (18) and transforming growth factor-beta (TGF $\beta$ ) (19). The molecular mechanisms of these events are complex and have not been fully elucidated.

In the present study, it was observed that the eluted S-PRG solution containing multiple ions promoted the migration, but not the proliferation, of HGF-1 cells. S-PRG fillers, composed of a powdery reaction product containing polyalkenoic acid and fluorine-containing glass, are characterized by sustained F release and have cariostatic properties (4). In fact, a previous study reported that an S-PRG filler containing flowable resin had a high level of F release as compared with other flowable resins tested (20). Furthermore, S-PRG filler is produced by an acid-base reaction between acid-reactive glass and polyacids in the presence of water (4), and has properties similar to glass ionomer cement (21). Given these properties, S-PRG filler can release Al, B, Na, Si and Sr ions, in addition to $\mathrm{F}$ ion, and therefore the solution eluted from this filler contains multiple ions. According to the results of the present study, it is thus suggested that the combination of these multiple ions promotes fibroblast migration. 
A

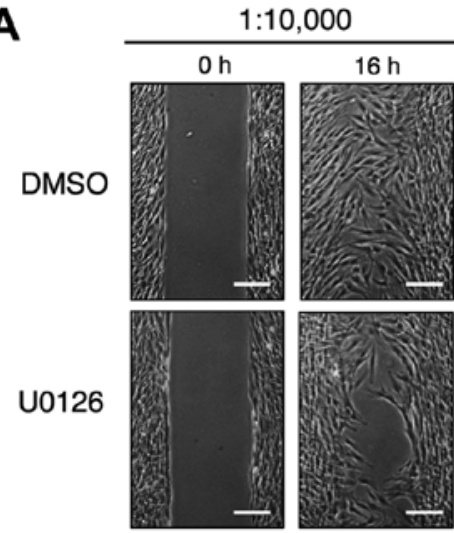

D

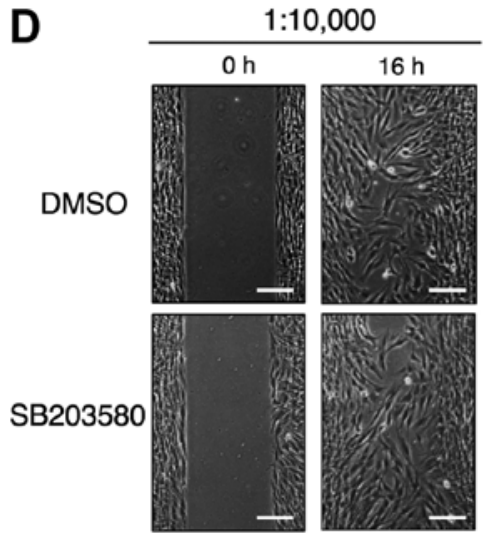

B

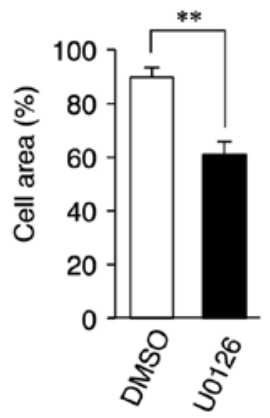

E

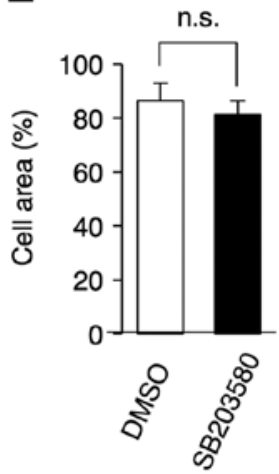

C

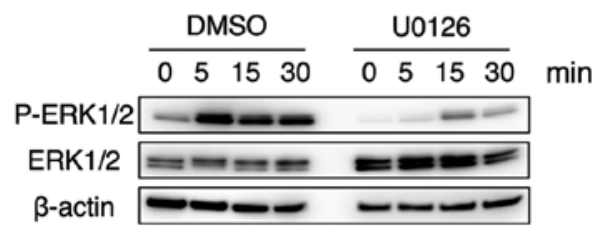

$\mathbf{F}$

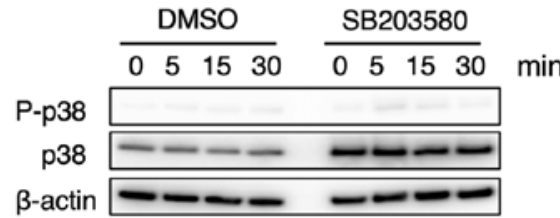

Figure 4. Inhibition of cell migration is induced by co-incubation with a MEK inhibitor and multiple-ion solution eluted from the S-PRG filler. HGF-1 cells were cultured in the presence of solution diluted to 1:10,000, and with or without $10 \mu \mathrm{M}$ U0126 (a MEK inhibitor) or SB203580 (a p38 MAPK inhibitor) for $16 \mathrm{~h}$. An equal volume of DMSO was added to the control cells. (A) Cell area percentage, (B) cell culture images (magnification, $\mathrm{x} 20$; scale bar, $200 \mu \mathrm{m})$, and (C) western blot results following incubation with U0126 are shown. (D) Cell area percentage, (E) cell culture images (magnification, x20; scale bar, $200 \mu$ m), and $(\mathrm{F})$ western blot results following incubation with SB203580 are displayed. To quantify cell migration, the uncovered area was measured using the Image software. The time course of ERK1/2 and p38 phosphorylation in the presence of U0126 and SB203580, respectively, was analyzed by western blotting. Values are presented as the mean \pm standard error of the mean $(n=4)$. Repeatability of the results obtained experimentally was confirmed by performing three independent trials. ${ }^{* *} \mathrm{P}<0.01$. S-PRG, surface pre-reacted glass-ionomer; HGF, human gingival fibroblast; ERK1/2, extracellular signal-regulated kinase 1/2; p-, phosphorylated; DMSO, dimethyl sulfoxide; n.s., not significant.

Extracellular ions are extracellular environment factors that have great effects on the physiological activity of cells (22-30). The respective influence of individual ions on cellular activity results in different effects depending on the conditions present, including concentration and combination with other ions. For instance, although $\mathrm{Al}$ is known to be a toxic agent (22), a previous study reported that micromolar concentrations of $\mathrm{Al}$ ions had a direct effect on osteoblasts, stimulating their proliferation and differentiation (23). Conversely, another study observed that low concentrations of $\mathrm{Al}$ ions induced no effects on osteoblast behaviors; however, in combination with titanium ions (Ti), Al enhanced the deleterious effects of Ti on osteoblast differentiation (24). Furthermore, long-term exposure to $\mathrm{F}$ ions $(>1 \mathrm{mM})$ inhibited the proliferation of L-929 fibroblasts, whereas short-term exposure stimulated the cell proliferation, with the stimulatory effect further enhanced by $1 \mu \mathrm{M} \mathrm{Al}$ ions (29). A low-dose $\mathrm{Sr}$ was also found to stimulate osteogenic differentiation, while higher doses induced apoptosis of human adipose-derived stem cells (30). Thus, extracellular ions have important functions in supporting fundamental cell activities and cell death, and a change in extracellular ion composition can have a great influence, either positive or negative, on affected cells.
ERK1/2, a member of the MAPK family, is a dynamic cell signaling pathway that functions with various cell responses, including proliferation, migration, differentiation and death (31). In the current study, the examined solution eluted from S-PRG filler promoted the phosphorylation of ERK1/2, but not of p38 MAPK. Furthermore, U0126 (a MEK inhibitor), but not SB203580 (a p38 MAPK inhibitor), inhibited cell migration induced by the solution. Several studies have indicated that the p38 inhibitors SB203580 and SB202190 also inhibited cell migration that was induced by pigment epithelium-derived factor PDGF, TGF $\beta$ and IL-1 $\beta$ (32-34). These results suggest that $\mathrm{p} 38$ is involved in cell migration, while it also has a principal role in growth factor or cytokine-induced cell migration. Although further studies are required to identify the molecular mechanism regulating cell migration in HGF-1, these results indicated that the activation of ERK signaling may be responsible for gingival fibroblast migration induced by the multiple ions in the solution examined in the present study.

Dental restorative materials are designed to have specific characteristics based on the biological, chemical and mechanical properties of their components, and must not trigger inflammation, toxic reactions or allergenic symptoms. However, those materials in fact often cause allergic reactions, 
with research in recent decades focusing on dental metals in particular. The intraoral environment is susceptible to sudden changes in temperature and $\mathrm{pH}$ caused by ingested food or drink, and is subjected to mechanical or electronic forces caused by occlusion, which have significant influence on the corrosion properties of dental metals (35). Furthermore, oxygen and chloride ions in saliva are involved in corrosion caused by chemical processes (36). The first reported dental metal allergy was in relation to mercury as part of amalgam dental materials, which was demonstrated to cause stomatitis and dermatitis (37). Thereafter, nickel, chromium, palladium and cobalt, commonly used as dental materials, were also reported to have associations with dental metal allergies (38). Resins are frequently used as an alternative dental material instead of metals, including methyl methacrylate, 2-hydroxyethyl methacrylate, ethylene glycol dimethacrylate and triethylene glycol dimethacrylate; however, these can also be a cause of allergies $(39,40)$. Allergic reactions caused by resins are mainly considered to be associated with an unreacted residual monomer (41).

For effective use, biomaterials should be harmless to the body; thus, the concept of the biocompatibility of biomaterials used in regenerative medicine (42), associated with proper response by surrounding tissues, has recently become an important issue. Second generation biomaterials are characterized by their resorbable or biological activity, while third generation materials possess both of these characteristics (43). For instance, hydroxyapatite, a widely-used bone graft biomaterial with excellent biocompatibility and osteoconductive properties, promotes self-healing processes (44). Thus, biomaterials are required to have bioactive properties to induce and regulate specific cellular responses at the molecular level, indicating that biocompatibility is an essential concept for the design of dental materials.

A limitation of the current study is that only in vitro experiments were conducted to evaluate the effect of the multiple ion-containing solution eluted from the S-PRG filler. Therefore, it is possible that a multiple-ion solution at a higher dilution than 1:10,000 or a different combination of ions may have a greater effect on cell migration. Furthermore, the current study did not focus on which ion eluted from filler affected HGF-1 cell migration. Mechanistic analysis to address whether the eluted multiple ions had a direct or indirect effect on cell migration is also lacking. The individual ion function and different combination of ions should be assessed in further studies.

In conclusion, the results of the present study demonstrated that the multiple ion-containing solution eluted from S-PRG filler promoted the migration of HGF-1 cells via the ERK1/2 signaling pathway, potentially promoting oral mucosa wound healing. These findings suggested that the application of such an S-PRG filler may contribute not only to the prevention of dental caries, but also to homeostasis of the oral mucosa. In addition, the present study provides useful information for the development of novel therapeutic drugs for oral diseases with materials composed of multiple ions.

\section{Acknowledgements}

Not applicable.

\section{Funding}

This study was supported by grants-in-aid (grant nos. $17 \mathrm{H} 04414$ and 15K11368) from the Ministry of Education, Science, and Culture of Japan.

\section{Availability of data and materials}

The datasets generated and analyzed in this study are available from the corresponding author upon reasonable request.

\section{Authors' contributions}

TI conceived and designed the experiments, analyzed the data, and drafted the manuscript. KYU, YA, KK, AS, HN, AM, RK, $\mathrm{KI}, \mathrm{TK}$ and TH performed the experiments, analyzed the data, prepared the figures and reviewed cited literature. AY and $\mathrm{SF}$ analyzed the data and reviewed drafts of the manuscript. All authors have read and approved the final version of the manuscript.

\section{Ethics approval and consent to participate}

Not applicable.

\section{Patient consent for publication}

Not applicable.

\section{Competing interests}

The authors declare that they have no competing interests.

\section{References}

1. Ara T, Kurata K, Hirai K, Uchihashi T, Uematsu T, Imamura Y, Furusawa K, Kurihara S and Wang PL: Human gingival fibroblasts are critical in sustaining inflammation in periodontal disease. J Periodontal Res 44: 21-27, 2009.

2. Soliman AM, Das S, Abd Ghafar N and Teoh SL: Role of MicroRNA in proliferation phase of wound healing. Front Genet 9: 38, 2018.

3. Heun Y, Pogoda K, Anton M, Pircher J, Pfeifer A, Woernle M, Ribeiro A, Kameritsch P, Mykhaylyk O, Plank C, et al: HIF-1a dependent wound healing angiogenesis in vivo can be controlled by site-specific lentiviral magnetic targeting of SHP-2. Mol Ther 25: 1616-1627, 2017.

4. Ikemura K, Tay FR, Endo T and Pashley DH: A review of chemical-approach and ultramorphological studies on the development of fluoride-releasing dental adhesives comprising new pre-reacted glass ionomer (PRG) fillers. Dent Mater J 27 : 315-339, 2008.

5. Salmerón-Valdés EN, Scougall-Vilchis RJ, Alanis-Tavira J and Morales-Luckie RA: Comparative study of fluoride released and recharged from conventional pit and fissure sealants versus surface prereacted glass ionomer technology. J Conserv Dent 19: 41-45, 2016.

6. Itota T, Carrick TE, Yoshiyama M and McCabe JF: Fluoride release and recharge in giomer, compomer and resin composite. Dent Mater 20: 789-795, 2004.

7. Alsayed EZ, Hariri I, Nakashima S, Shimada Y, Bakhsh TA, Tagami J and Sadr A: Effects of coating materials on nanoindentation hardness of enamel and adjacent areas. Dent Mater 32: 807-816, 2016.

8. Nomura R, Morita Y, Matayoshi S and Nakano K: Inhibitory effect of surface pre-reacted glass-ionomer (S-PRG) eluate against adhesion and colonization by Streptococcus mutans. Sci Rep 8: 5056, 2018. 
9. Tsutsumi C, Takakuda K and Wakabayashi N: Reduction of Candida biofilm adhesion by incorporation of prereacted glass ionomer filler in denture base resin. J Dent 44: 37-43, 2016.

10. Kawasaki $\mathrm{K}$ and Kambara $\mathrm{M}$ : Effects of ion-releasing tooth-coating material on demineralization of bovine tooth enamel. Int J Dent 2014: 463149, 2014

11. Hashimura T, Yamada A, Iwamoto T, Arakaki M, Saito K and Fukumoto S: Application of a tooth-surface coating material to teeth with discolored crowns. Pediat Dent J 23: 44-50, 2013.

12. Hirayama K, Hanada T, Hino R, Saito K, Kobayashi M, Arakaki M, Chiba Y, Nakamura N, Sakurai T, Iwamoto T, et al Material properties on enamel and fissure of surface pre-reacted glass-ionomer filler-containing dental sealant. Pediat Dent J 28 : $87-95,2018$.

13. Iwamatsu-Kobayashi Y, Abe S, Fujieda Y, Orimoto A Kanehira M, Handa K, Venkataiah VS, Zou W, Ishikawa M and Saito M: Metal ions from S-PRG filler have the potential to prevent periodontal disease. Clin Exp Dent Res 3: 126-133, 2017.

14. Huang C, Jacobson K and Schaller MD: MAP kinases and cell migration. J Cell Sci 117: 4619-4628, 2004

15. Iwatsuki $M$ and Matsuoka M: Fluoride-induced c-Fos expression in MC3T3-E1 osteoblastic cells. Toxicol Mech Methods 26 $132-138,2016$

16. Ware MF, Wells A and Lauffenburger DA: Epidermal growth factor alters fibroblast migration speed and directional persistence reciprocally and in a matrix-dependent manner. J Cell Sci 111: 2423-2432, 1998.

17. Tan SS, Yeo XY, Liang ZC, Sethi SK and Tay SSW: Stromal vascular fraction promotes fibroblast migration and cellular viability in a hyperglycemic microenvironment through up-regulation of wound healing cytokines. Exp Mol Pathol 104: 250-255, 2018

18. Suetsugu S, Yamazaki D, Kurisu S and Takenawa T: Differential roles of WAVE1 and WAVE2 in dorsal and peripheral ruffle formation for fibroblast cell migration. Dev Cell 5: 595-609, 2003.

19. Acharya PS, Majumdar S, Jacob M, Hayden J, Mrass P, Weninger W, Assoian RK and Puré E: Fibroblast migration is mediated by CD44-dependent TGF beta activation. J Cell Sci 121: 1393-1402, 2008

20. Nakamura N, Yamada A, Iwamoto T, Arakaki M, Tanaka K Aizawa S, Nonaka K and Fukumoto S: Two-year clinical evaluation of flowable composite resin containing pre-reacted glass-ionomer. Pediat Dent J 19: 89-97, 2008

21. Billington RW, Williams JA and Pearson GJ: Ion processes in glass ionomer cements. J Dent 34: 544-555, 2006.

22. Yokel RA: The toxicology of aluminum in the brain: A review. Neurotoxicology 21: 813-828, 2000

23. Lau KH, Yoo A and Wang SP: Aluminum stimulates the proliferation and differentiation of osteoblasts in vitro by a mechanism that is different from fluoride. Mol Cell Biochem 105: 93-105, 1991.

24. Saldaña L, Barranco V, García-Alonso MC, Vallés G, Escudero ML, Munuera L and Vilaboa N: Concentrationdependent effects of titanium and aluminium ions released from thermally oxidized Ti6A14V alloy on human osteoblasts. J Biomed Mater Res A 77: 220-229, 2006.

25. Benderdour M, Hess K, Dzondo-Gadet M, Nabet P, Belleville $F$ and Dousset B: Boron modulates extracellular matrix and TNF alpha synthesis in human fibroblasts. Biochem Biophys Res Commun 246: 746-751, 1998.
26. Nzietchueng RM, Dousset B, Franck $P$, Benderdour M, Nabet $P$ and Hess K: Mechanisms implicated in the effects of boron on wound healing. J Trace Elem Med Biol 16: 239-244, 2002.

27. Denker SP and Barber DL: Cell migration requires both ion translocation and cytoskeletal anchoring by the $\mathrm{Na}-\mathrm{H}$ exchanger NHE1. J Cell Biol 159: 1087-1096, 2002.

28. Quignard S, Coradin T, Powell JJ and Jugdaohsingh R: Silica nanoparticles as sources of silicic acid favoring wound healing in vitro. Colloids Surf B Biointerfaces 155: 530-537, 2017.

29. Kawase T and Suzuki A: Studies on the transmembrane migration of fluoride and its effects on proliferation of L-929 fibroblasts (L cells) in vitro. Arch Oral Biol 34: 103-107, 1989.

30. Aimaiti A, Maimaitiyiming A, Boyong X, Aji K, Li C and Cui L: Low-dose strontium stimulates osteogenesis but high-dose doses cause apoptosis in human adipose-derived stem cells via regulation of the ERK1/2 signaling pathway. Stem Cell Res Ther 8: 282, 2017.

31. Murphy LO and Blenis J: MAPK signal specificity: The right place at the right time. Trends Biochem Sci 31: 268-275, 2006.

32. Hedges JC, Dechert MA, Yamboliev IA, Martin JL, Hickey E, Weber LA and Gerthoffer WT: A role for p38(MAPK)/HSP27 pathway in smooth muscle cell migration. J Biol Chem 274: 24211-24219, 1999

33. Kotlyarov A, Yannoni Y, Fritz S, Laass K, Telliez JB, Pitman D, Lin LL and Gaestel M: Distinct cellular functions of MK2. Mol Cell Biol 22: 4827-4835, 2002.

34. Konson A, Pradeep S, D'Acunto CW and Seger R: Pigment epithelium-derived factor and its phosphomimetic mutant induce JNK-dependent apoptosis and P38-mediated migration arrest. Cell Physiol Biochem 49: 512-529, 2018.

35. Kedici SP, Aksüt AA, Kílíçarslan MA, Bayramoğlu G and Gökdemir K: Corrosion behaviour of dental metals and alloys in different media. J Oral Rehabil 25: 800-808, 1998.

36. Porcayo-Calderon J, Casales-Diaz M, Salinas-Bravo VM and Martinez-Gomez L: Corrosion performance of $\mathrm{Fe}-\mathrm{Cr}-\mathrm{Ni}$ alloys in artificial saliva and mouthwash solution. Bioinorg Chem Appl 2015: 930802, 2015.

37. Syed M, Chopra R and Sachdev V: Allergic reactions to dental materials-a systematic review. J Clin Diagn Res 9: ZE04-ZE09, 2015.

38. Zhang X, Wei LC, Wu B, Yu LY, Wang XP and Liu Y: A comparative analysis of metal allergens associated with dental alloy prostheses and the expression of HLA-DR in gingival tissue. Mol Med Rep 13: 91-98, 2016.

39. Leggat PA and Kedjarune U: Toxicity of methyl methacrylate in dentistry. Int Dent J 53: 126-131, 2003.

40. Marquardt W, Seiss M, Hickel R and Reichl FX: Volatile methacrylates in dental practices. J Adhes Dent 11: 101-107, 2009.

41. Nik TH, Shahroudi AS, Eraghihzadeh Z and Aghajani F: Comparison of residual monomer loss from cold-cure orthodontic acrylic resins processed by different polymerization techniques. J Orthod 41: 30-37, 2014.

42. Williams DF: There is no such thing as a biocompatible material. Biomaterials 35: 10009-10014, 2014

43. Hench LL and Polak JM: Third-generation biomedical materials. Science 295: 1014-1017, 2002.

44. Oliveira HL, Da Rosa WLO, Cuevas-Suárez CE, Carreño NLV, da Silva AF, Guim TN, Dellagostin OA and Piva E: Histological evaluation of bone repair with hydroxyapatite: A systematic review. Calcif Tissue Int 101: 341-354, 2017. 